Indonesian Journal of Physics and Nuclear Applications

Volume 3, Number 1, February 2018, p. 7-14

e-ISSN 2550-0570, (C) FSM UKSW Publication

\title{
Study on the Ability of PCMSR to Produce Valuable Isotopes as a By Product of Energy Generation
}

\author{
Andang Widi Harto \\ Department of Nuclear Engineering and Physics Engineering, Faculty of \\ Engineering UGM, Jln. Grafika No.2, Yogyakarta, DIY, 55281, Indonesia
}

\begin{abstract}
PCMSR (Passive Compact Molten Salt Reactor) is a variant of MSR (Molten Salt Reactor) type reactors. The MSR is one type of the Advanced Nuclear Reactor types. PCMSR uses mixtures of fluoride salt if the liquid form is in a high temperature operation. The use of liquid salt fuel allows the application of on line fuel processing system. The on line fuel processing system allows extraction of several valuable fission product isotopes such as Mo-99, Cs-137, Sr-89 etc. The capability of MSR to produce several valuable isotopes has been studied. This study is based on a denaturized breeder MSR design with 920 MWth of thermal power and $500 \mathrm{MWe}$ of electrical output power with the thermal efficiency of $55 \%$. The initial composition of fuel salt is $70 \%$ of a mole of LiF, $24 \%$ of a mole of ${ }^{232} \mathrm{ThF} 4,6 \%$ of a mole of $U_{4}$. The enrichment level of $U$ is $20 \%$ of a mole of $U-235$. The study is performed by a numerical calculation to solve a set of differential equations of fission product balance. This calculation calculates fission product generation due to fission reaction, precursor decay, and fission product annihilation due to decay, neutron absorption, and extraction. The calculation result shows that in quasi equilibrium conditions, the reactor can produce several valuable isotopes in substantially sufficient quantities, those are $\mathrm{Sr}-89$ (0.3 kCi/MWth/day, $\mathrm{Sr}-90$ (1,91 Ci/MWth/day), Mo-99 (1.7 kCi/MWth/day), I-131 (0.42 kCi/MWth/day), I-132 (0.782 kCi/MWth/day), I-133 (1.12 kCi/MWth/day), Xe-133 (11.8 Ci/MWth/day), Cs-134 (39.3 mCi/MWth/day), Cs-137 (2.32 Ci/MWth/day) and La-140 (1.05 kCi/MWth/day).
\end{abstract}

Keywords PCMSR, fission product, valuable nuclides

\section{INTRODUCTION}

The worldwide human civilization recently posed a serious energy problem i.e. the increased energy demand and high dependence on conventional (coal, oil and natural gas) energy resources [1]. The diminishing of resources and the serious environmental effect such as global warming are the two most important factors to reduce the utilization of conventional energy resources. Other energy resources must be provided to replace conventional energy resources. Nuclear energy will become the prominent alternative because nuclear technology has been proven technologically and economically.

The recent nuclear technology is based on non-breeder reactors that use low enrichment uranium (LEU). Three serious problems will arise as the consequences of long term utilization of the recent nuclear technology, the sustainability problem, a long living radioactive waste problem, and a proliferation problem. The sustainability problem will arise due to the fact that the recent nuclear technology can only utilize U-235 which exist in only $0.7 \%$ of a mole of natural uranium. The known worldwide uranium resources, 7600 kilotons [2] can supply a nuclear energy generation with the recent capacity of 376 GWe [3] for only 50 to 80 years [4]. 
The capability of the recent nuclear technology to utilize only U-235 means that more than $99 \%$ of nuclear resource materials will be unusable. Roughly, $12 \%$ of the mined nuclear resources will become spent fuel and the rest will become unusable depleted uranium. The properly used U-238 will become long term radioactive waste in nuclear spent fuel as well and will become weapon grade $\mathrm{Pu}-.239$. The natural fertile thorium, which is more abundant than natural uranium cannot be used by the recent nuclear technology. The use of thorium as a major fertile fuel will solve the three major problems resembled in the recent nuclear technology.

On the other side, the need of several valuable isotopes is sharply increased. For example Mo-99 is one of the more valuable isotopes as it become the precursor of Tc$99 \mathrm{~m}$. More than $80 \%$ of medical diagnostic use Tc-99m and the world demand is predicted to increase in the future [5]. Other valuable isotopes in medical uses are $\mathrm{Sr}-89$, Sr-90, I-131, I-132, I-133, Xe-133. Some valuable isotopes are for industrial uses such as Cs-134, Cs-137 and La-140

PCMSR (Passive Compact Molten Salt Reactor) is a variant of MSR (Molten Salt Reactor) type reactors. The MSR is one type of the Advanced Nuclear Reactor. PCMSR is a breeder type MSR optimized to utilize Th232 as fertile fuel. PCMSR is equipped with on line fuel processing which allows for the extraction of several valuable isotopes. Thus, PCMSR can produce several valuable isotopes as well as electricity.

\section{MATERIALS AND METHODS}

\subsection{PCMSR (Passive Compact Molten Salt} Reactor)
PCMSR (Passive Compact Molten Salt Reactor) is optimized to use Th-232 as the major fertile fuel. The Th-232 will be converted to the fissile U-233 in such a way so that the rate of conversion will be slightly larger than the rate of U-233 consumption (i.e. breeder condition is achieved). Due to the fact that U-233 does not exist naturally, other fissile fuel is needed during the initial phase of operation. Several options of initial fissile fuel to be used for MSR have been studied [6]. To avoid the use of weapon grade fissile fuel, the LEU (low enriched uranium) will be used as the initial fissile fuel of PCMSR. PCMSR uses mixture of liquid fluoride salt. The initial composition of fuel salt is $70 \%$ mole of LiF, $24 \%$ mole of ${ }^{232} \mathrm{ThF} 4,6 \%$ mole of UF4. The enrichment level of $U$ is $20 \%$ mole of ${ }^{235} \mathrm{U}$. PCMSR uses graphite as moderator and structure and eutectic flinak salt (LiF-NaK-KF) as intermediate coolant [7].

Due to the high boiling point of molten salt, high sublimation point of graphite, low neutron absorption cross section of both of molten salt and graphite, and low fissile fuel to fertile fuel concentration ratio, MSR and PCMSR design have several benefits. These are, low pressure and high temperature operation [8], high breeding ratio [9], inherent safety [9], high thermal efficiency [8], flexibility in output energy utilization [9] and production of fewer minor actinides than the use of ${ }^{238} U$ as fertile fuel [6]. Due to its breeding capability, the PCMSR waste is dominated by fission product with far shorter lifetime and a far smaller amount than the spent fuel of the recent LWR reactor.

The PCMSR is designed to apply the concepts of integral and modularity. PCMSR has three main modules, i.e. reactor module, turbine module and fuel management module. The 
reactor module consists of an integral reactor and its relative safety system. The fuel management module consists of fuel processing system and fission product waste management system. The reactor module and the fuel management module are located inside the reactor building. Due to the high temperature of operation, PCMSR uses a multistage regenerative Brayton gas turbine rather than the Rankine steam turbine commonly used in recent reactor technology. The turbine module consists of an integral turbinecompressor and heat exchanger set and is located inside the turbine building. Figure 1 shows the schematic diagram of PCMSR [7].

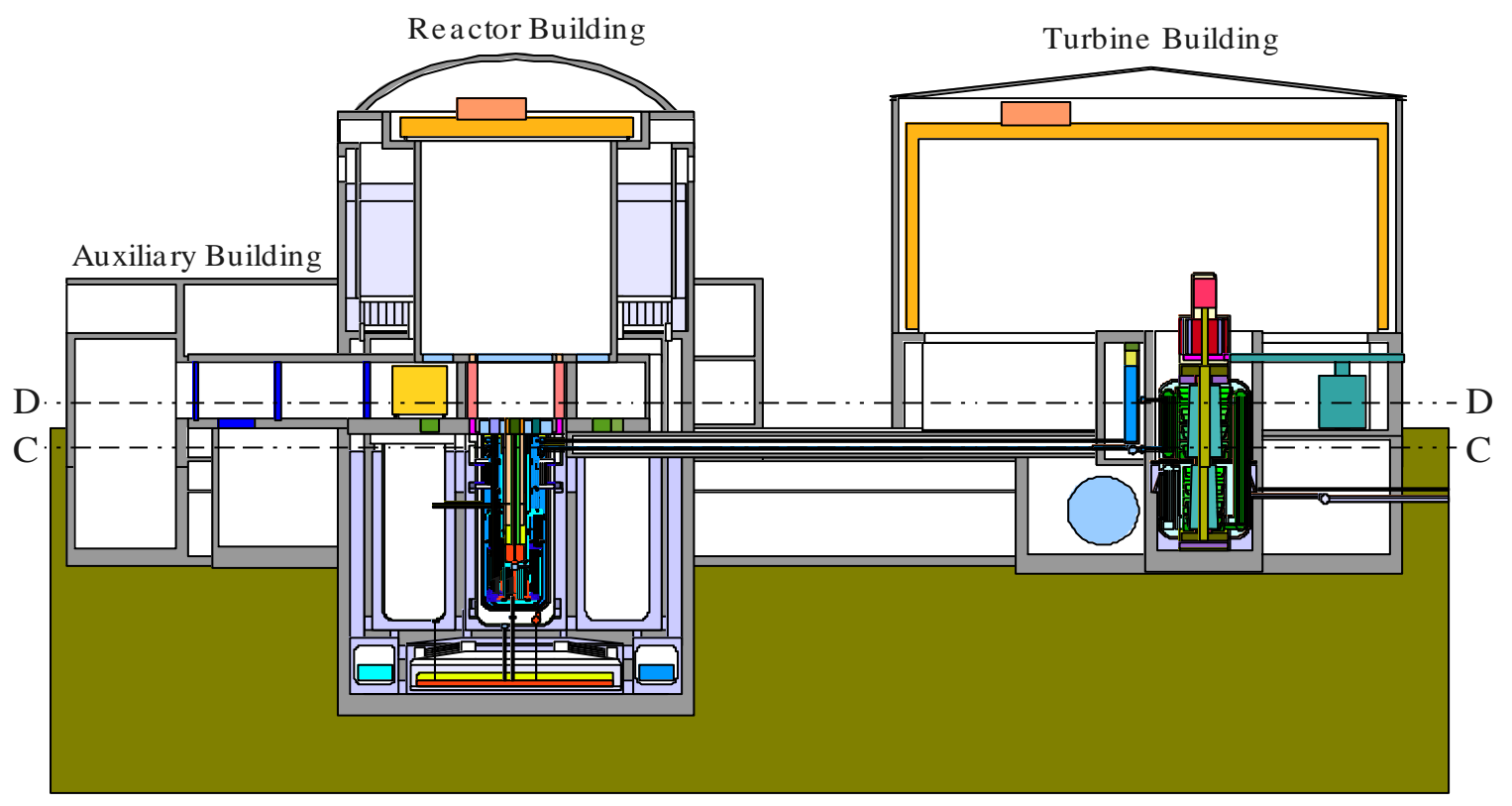

Figure 1. Overall configuration of Modular 250 MWe PCMSR system [7]

The on line processing system is the important part for the PCMSR to be successfully operated as a breeder reactor. The on line processing system consists of a fuel feeding system, a Pa extraction system, a fission product extraction system and a waste processing system. The feeding system is used to continually feed the fertile fuel. Fissile fuel is loaded only as initial fuel.

The $\mathrm{Pa}$ extraction system is used to extract $\mathrm{Pa}-233$ to prevent it from neutron irradiation. The Pa-233 is a slightly strong neutron absorber. Allowing Pa-233 to stay in reactor gives two disadvantages, reducing reactor criticality and the Pa-233 will finally become unusable U-234. By extracting Pa-233, the existence of $\mathrm{Pa}-233$ in reactor can be limited and $\mathrm{Pa}-233$ will decay to fissile isotope U-233. The U-233 is then sent back to the reactor.

After Pa-extraction, the fuel is sent to fission product extraction system. This system will produce significant amount of several fission product. The purpose of the fission product extraction system is mainly to prevent the reactor from neutron poisoning by the fission product. However, this system gives another 
benefit. Several valuable fission product isotopes for human civilization can be picked out from the extraction system to be utilized for several purposes such as medicine, industry, research, etc. The unused fission isotopes are considered radioactive waste and will be directly sent to the waste treatment system. Figure 2 shows the schematic diagram of the PCMSR on line refueling and on line fuel processing system.

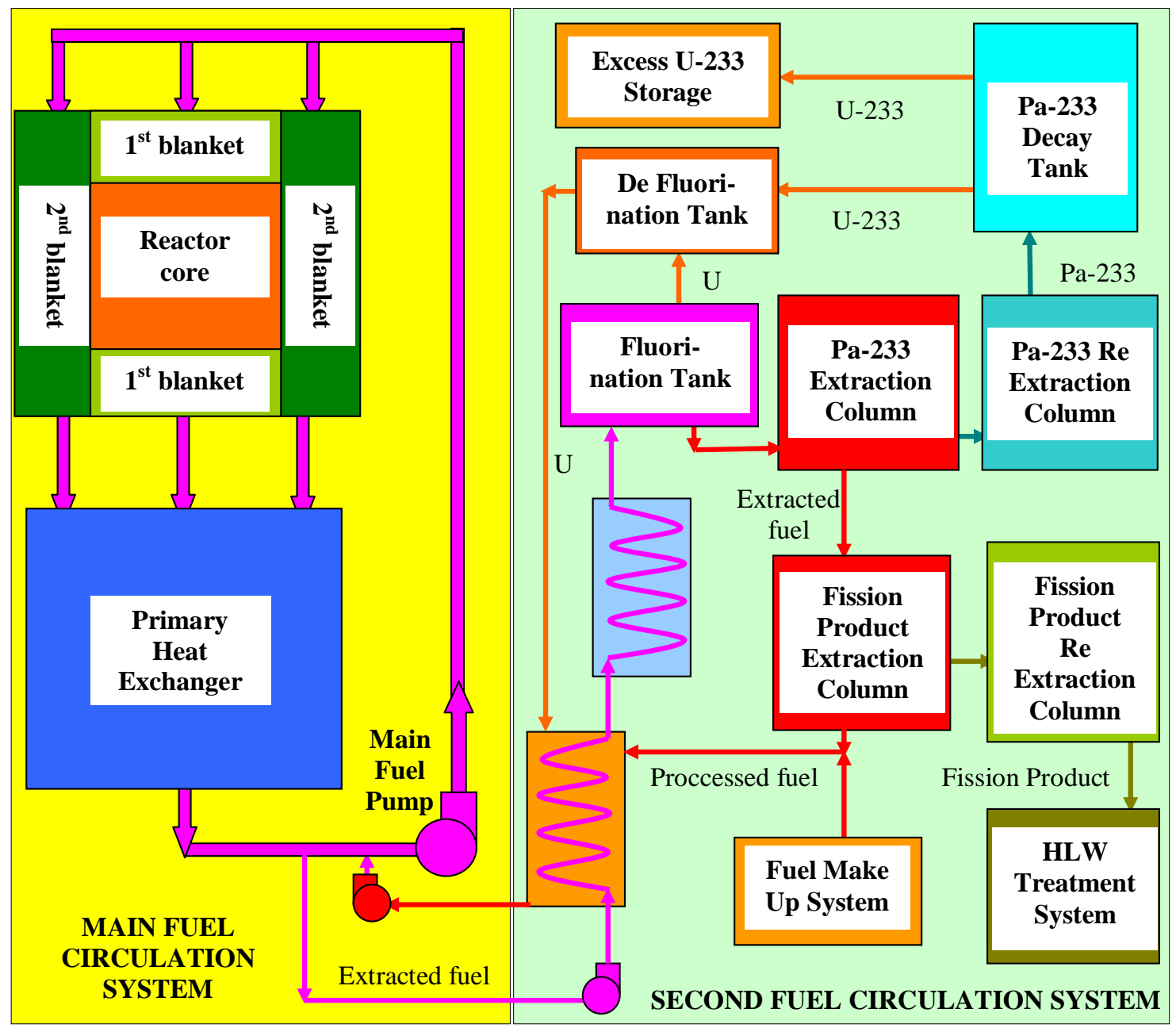

Figure 2. The schematic diagram of the PCMSR on line refueling and on line fuel reprocessing system [7] (with modification)

\subsection{Procedure}

The procedure consists of three steps: construction of a set of differential equations of nuclide balances in the reactor, solving the differential equation numerically and calculation of the extraction of same valuable isotopes.

\section{Step 1.}

The first step is construction of a set of differential equations of nuclide balances in reactor. The nuclides treated in this study are in two groups, actinides and fission products. The actinides exist in initial PCMSR fuel as Th-232, U-235 and U-238. The fertile nuclides such as U-238 and Th-232 absorb neutron and transmute 
to become other nuclides. The fissile nuclides absorb neutron and undergo fission reaction to become several fission products. There are two groups of fission products, light fission products with mass numbers between 80 and
124 and heavy fission products with mass numbers between 124 and 160 . The general form of nuclide balance equation is formulated by equation 1 .

$$
\begin{gathered}
\frac{d}{d t}\left(V_{C} \Omega_{F C}+V_{B 1} \Omega_{F B 1}+V_{B 2} \Omega_{F B 2}+V_{H} \Omega_{F H}+V_{E}\right) N_{Z, A} \\
=\sum_{i=1}^{I} Q_{i n, i} N_{i n, i, Z, A}-\sum_{k}^{K} Q_{o u t, k} N_{Z, A} \\
-N_{Z, A} \sum_{g=1}^{G} \sigma_{a, g, Z, A}\left(\int_{V_{C}} \varphi_{g C} \zeta_{C, g} d V_{C}+\int_{V_{B 1}} \varphi_{g B 1} \zeta_{B 1, g} d V_{B 1}+\int_{V_{B 2}} \varphi_{g B 2} \zeta_{B 2, g} d V_{B 2}\right)+ \\
\left(\begin{array}{c}
\left.-\lambda_{Z, A} N_{Z, A}+\lambda_{Z-1, A} N_{Z-1, A} f_{\beta^{-}, Z, A-1}+\lambda_{Z+1, A} N_{Z+1, A} f_{\beta^{+}, Z+1, A}\right) \\
+\lambda_{Z+2, A+4} N_{Z+2, A+4} f_{\alpha, Z+2, A+4} \\
+\lambda_{Z, A+1} N_{Z, A+1} f_{n, Z, A+1}+\lambda_{Z, A+2} N_{Z, A+2} f_{2 n, Z, A+2}+V_{B 1} \Omega_{F B 1}+ \\
V_{B 2} \Omega_{F B 2}+V_{H} \Omega_{F H}+V_{E}
\end{array}\right) \\
+N_{Z, A-1} \sum_{g=1}^{G}\left(\sigma_{a, g, Z, A-1}-\sigma_{f, g, Z, A-1}\right)\left(\int_{V_{C}} \varphi_{g C} \zeta_{C, g} d V_{C}+\int_{V_{B 1}} \varphi_{g B 1} \zeta_{B 1, g} d V_{B 1}+\int_{V_{B 2}} \varphi_{g B 2} \zeta_{B 2, g} d V_{B 2}\right) \\
+\sum_{j=1}^{J} N_{Z_{j}, A_{j}} \sum_{g=1}^{G} y_{Z, A, Z_{j}, A_{j}, g} \sigma_{f, g, Z_{j}, A_{j}}\left(\int_{V_{C}} \varphi_{g C} \zeta_{C, g} d V_{C}+\int_{V_{B 1}} \varphi_{g B 1} \zeta_{B 1, g} d V_{B 1}+\int_{V_{B 2}} \varphi_{g B 2} \zeta_{B 2, g} d V_{B 2}\right)
\end{gathered}
$$

Where:

A : Mass Number

$g \quad:$ Index of group energy of neutron

$i$ : Index of inlet flow to reactor system

$k \quad:$ Index of outlet flow from reactor system

$j \quad:$ Index of fissionable nuclei

$V_{C} \quad$ : Reactor core volume $\left(\mathrm{cm}^{3}\right)$

$V_{B 2}:$ Second blanket volume $\left(\mathrm{cm}^{3}\right)$

$\Omega_{F C}:$ Fuel volume fraction of reactor core

$\Omega_{F B}$ : Fuel volume fraction of second blanket

$N \quad$ : Nuclide density (nuclide $/ \mathrm{cm}^{3}$ ) $\sigma_{a} \quad$ : Microscopic neutron absorption cross section $\left(\mathrm{cm}^{2}\right)$

$\sigma_{f}:$ Microscopic fission cross section $\left(\mathrm{cm}^{2}\right)$

$y \quad$ : Fission product yield

$\lambda \quad$ : Decay constant $\left(\mathrm{s}^{-1}\right)$

$\zeta_{C}:$ Neutron flux depression factor of core

$\zeta_{B 1}:$ Flux depression factor of first blanket

$\zeta_{B 2}:$ Flux depression factor of second blanket

$Q_{\text {in }}:$ Fuel inlet volumetric flow rate $\left(\mathrm{cm}^{3} / \mathrm{s}\right)$

$Z$ : Atomic number

$G \quad$ : Number of neutron energy group 
I : Number of inlet flow to reactor system

$K \quad$ : Number of outlet flow to reactor system

$J \quad$ : Number of fissionable nuclei

$V_{B 1}$ : First blanket volume $\left(\mathrm{cm}^{3}\right)$

$V_{H}$ : Primary heat exchanger volume $\left(\mathrm{cm}^{3}\right)$

$\Omega_{F B}$ : Fuel volume fraction of first blanket

$\Omega_{F H}$ : Fuel volume fraction of primary heat exchanger

$f_{\beta^{-}}:$Negative beta decay fraction

$f_{\beta^{+}}$: Positive beta decay fraction

$f_{\alpha} \quad$ : Alpha decay fraction

$f_{n} \quad$ : One neutron emission decay fraction

$f_{2 n}$ : Two neutrons emission decay fraction

$\phi_{g C}:$ Aberage neutron flux in reactor core $\left(\mathrm{n} /\left(\mathrm{cm}^{2} \cdot \mathrm{s}\right)\right)$

$\phi_{g B 1}$ : Average neutron flux in first blanket $\left(\mathrm{n} /\left(\mathrm{cm}^{2} \cdot \mathrm{s}\right)\right)$

$\phi_{g B 2}:$ Average neutron flux in second blanket $\left(\mathrm{n} /\left(\mathrm{cm}^{2} . \mathrm{s}\right)\right)$

$Q_{\text {out }}$ : Fuel outlet volumetric flow rate $\left(\mathrm{cm}^{3} / \mathrm{s}\right)$

Step 2.

There are a total of 227 isotopes involved in this calculation, including 40 actinide isotopes, 90 light fission product isotopes, 97 heavy fission products. Thus, there are a total of 227 isotope balance equations to be solved simultaneously. The solution is performed using PCMSRBU software. The solution result is the nuclide density of isotopes in the reactor.
Step 3.

Step 3 calculates the amount of a special isotopes that can be selected by the on line fission product extraction system to be utilized as valuable isotopes. This amount are formulated as :

$$
E_{X C, F P, Z, A}=\frac{\lambda_{Z, A} f_{C Z} \eta_{C Z}\left(1-\eta_{P Z}\right)\left(1-\eta_{F Z}\right) Q_{r e p r} N_{Z, A}}{3.7 \times 10^{-10} Q_{R}}
$$

Where: $\begin{aligned} E_{X C, F P, Z, A}: & \text { activity of isotope with atomic } \\ & \text { number } Z \text { and mass number } A \text { that }\end{aligned}$ can be picked by the on line fission product extraction system to be utilized as valuable isotopes (Ci/MWth)

$f_{C Z} \quad$ : picking fraction of isotope with atomic number $Z$

$\eta_{F Z} \quad$ : extraction efficiency of isotope with atomic number $Z$ by fluorination system

$\eta_{P Z} \quad:$ extraction efficiency of isotope with atomic number $Z$ by $\mathrm{Pa}$ extraction system

$\eta_{C Z} \quad$ : extraction efficiency of isotope with atomic number $Z$ by fission product extraction system

$Q_{\text {repr }} \quad$ : fuel processing volume flow rate $\left(\mathrm{cm}^{3} / \mathrm{s}\right)$

$\lambda_{Z, A} \quad:$ decay constant of isotope with atomic number $Z$ and mass number $A(1 / \mathrm{s})$

$Q_{R} \quad$ : reactor thermal power (MWth)

\section{RESULTS AND DISCUSSION}

The calculation is performed for PCMSR with the thermal power of $460 \mathrm{MWe}$ and the electrical power output of $250 \mathrm{MWe}$, with the energy conversion efficiency is $55 \%$. The initial composition of fuel salt is $70 \%$ mole of LiF, 24 $\%$ mole of $232 \mathrm{ThF} 4,6 \%$ mole of UF4. The enrichment level of $U$ is $20 \%$ mole of $U-235$. The total specific fuel inventory in reactor core, blanket and primary heat exchanger is $55 \mathrm{~kg}$ of 
actinides per MWth.

A fluorination system is needed to extract uranium to prevent it from further extraction process. The extracted uranium is then defluorinated and loaded back into reactor. Volatile and gaseous fission product such as $\mathrm{Xe}, \mathrm{I}, \mathrm{Sr}$ and $\mathrm{Cs}$ isotopes are mostly extracted by the fluorination system, thus it is assumed that the extraction system of these isotopes by the fluorination system is high (99\%). The other fission products are assumed not to be extracted by the fluorination system and the efficiency for these isotopes is assumed to be very low (0\%).

$\mathrm{Pa}$ extraction system is designed to extract $\mathrm{Pa}$. The fission products are assumed not to be extracted by the system and the efficiency of the fission products isotopes by this system is assumed to be very low (0\%).

The fission product extraction system is designed to have capability to extract most of fission products. The extraction efficiency is assumed to be very high. Several desired fission products such as Mo-99 and La-140 are selected to be utilized as valuable isotopes. Thus, the selection factors of these isotopes are assumed to be high (90\%). The rest of the fission products are not utilized and will be treated as radioactive waste. The selection factors of these fission products are assumed to be very low (0\%).

To overcome the fissile fuel depletion due to fission reaction, the fertile fuel (Th-232) must be fed continually to the reactor by the reactor feeding system. The numerical solution for actinide isotopes shows that to maintain fissile material density in constant value, the specific mass flow rate of Th-232 to be fed is $0.8 \mathrm{~kg}$ per MWe per year. Thus, for PCMSR with 250 MWe output electrical power, the Th-232 needed is $200 \mathrm{~kg} /$ year. The fuel processing volume flow rate $\left(Q_{\text {repr }}\right)$ is assumed to be 2000 $\mathrm{cm}^{3} / \mathrm{s}$.

The valuable isotopes to be calculated are Sr-89, Sr-90, Mo-99, I-231, I-132, I-133, Xe133, Cs-134, Cs137 and La-140. Almost all of these isotopes are utilized for medical purposes. The Cs-134, Cs-137 and La-140 are used for industrial purposes. The calculation result is shown at Table 1. These amounts are quite significant. For example, half of Mo-99 demand recently in USA is 3000 six day $\mathrm{Ci}(12 \mathrm{kCi})$ [10]. Thus the $1.7 \mathrm{kCi} / \mathrm{Mwe} / \mathrm{day}$ is sufficient to meet the Mo-99 demand.

Table 1. Production rate of several valuable isotopes as by product of PCMSR power reactor

\begin{tabular}{cccc}
\hline Valuable isotopes & $\begin{array}{c}\text { Specific production rate } \\
(\mathrm{kCi} / \text { MWth/day })\end{array}$ & $\begin{array}{c}\text { Valuable } \\
\text { isotopes }\end{array}$ & $\begin{array}{c}\text { Specific production rate } \\
(\mathrm{kCi} / \mathrm{MWth} / \mathrm{day})\end{array}$ \\
\hline Sr-89 & 0.3 & $\mathrm{I}-133$ & 1.12 \\
Sr-90 & 0.00191 & $\mathrm{Xe}-133$ & 0.0118 \\
Mo-99 & 1.7 & $\mathrm{Cs}-134$ & 0.0000393 \\
$\mathrm{I}-131$ & 0.42 & $\mathrm{Cs}-137$ & 0.00232 \\
$\mathrm{I}-132$ & 0.782 & La-140 & 1.05
\end{tabular}

\section{CONCLUSION}

The PCMSR can produce several valuable 
isotopes from fission reaction as a by- product of power generation. The $250 \mathrm{MWe}$ PCMSR can produce several valuable isotopes, such as Sr-89 (0.3 kCi/MWth/day, Sr-90 (1,91 Ci/MWth/day), Mo-99 (1.7 kCi/MWth/day), I-131 (0.42 kCi/MWth/day), I-132 (0.782 $\mathrm{kCi} / \mathrm{MWth} /$ day), I-133 (1.12 kCi/MWth/day), Xe-133 (11.8 Ci/MWth/day), Cs-134 (39.3 $\mathrm{mCi} / \mathrm{MWth} /$ day), Cs-137 (2.32 Ci/MWth/day) and La-140 (1.05 kCi/MWth/day).

\section{REFERENCES}

1. World Energy Resources and Consumption Wikipedia, free encyclopedia, Chapter 1. Consumption

2. IAEA and OECD-NEA (2014) Uranium 2014: Resources, Production and Demand, A Joint Report by OECD Nuclear Energy Agency and the International Atomic Energy Agency, Paris,p.20.

3. IAEA (2015) Nuclear Power Reactors in the World, Reference Data Series No. 2, 2015 ed.,International Atomic Energy Agency, Vienna, pp.11-20

4. Zittel, W. and Schindler, J (2006) Uranium Resources and Nuclear Energy, EWG Paper No 1-06, Energy Watch Group, Berlin

5. IAEA, 2008, Homogeneous Aqueous Solution Nuclear Reactors for the Production of Mo-99 and Other Short Lived Radioisotopes, IAEA Tecdoc 1601, IAEA, Vienna, 2008

6. Luccote, E.M., Heuer, D., Allibert, M., Ghetta, V., Le Burn, C., Brissot, R., Liatard, E., Mathieu, M., 2007, the thorium molten salt reactor: Launching the thorium cycle while closing the current fuel cycle, HAL archives.

7. Harto. A., 2015, Sustainable Criticality Analysis Of PCMSR Fuel Using Thorium As Sustainable Fuel And Low Enrich Uranium As Starting Fuel, International Journal of Nuclear Energy Science and Technology (IJNEST), Vol. 9, No. 3 (2015) pp. $224-237$.

8. Benes, O., Cabet, C., Delpech, S., Hosnedl, P., Ignatiev, P., Konings, R., Lecarpentier, D., Matal, O., Merle-Lucotte, E., Renault, C., Uhlir, J., 2009, Aseessment of Liquid salts for Innovative Application ALISIA Deliverable (D50), Review Report on Liquid Salts for Various Applications

9. Forsbeg, C. W., Peterson, P. F., Zhao, H.H., 2004, An Advanced Molten Salt Reactor Using
High Temperature Reactor Technology, ICAPP.2004.MSR.Paper, 2004 International Congress on Advanced in Nuclear Power Plants (ICAPP'04) Embedded International Topical Meeting, 2004 American Nuclear Society Annual Meeting, Pittsburgh, Pennsylvania

10. Parrish Staples, 2010, Global Threat Reduction Initiative, IAEA Consultancy Meeting on Conversion Planning for Mo-99 Production Facilities from HEU to LEU 